\title{
El arreglo pacífico de controversias en el Sáhara Occidental, zintractable conflicto es aún posible una solución?*
}

\author{
Peace settlement of disputes in Western Sahara, intractable \\ conflict or it is possible to reach a solution?
}

\author{
Carolina JimÉnEZ SÁNCHEZ \\ Profesora de Derecho Internacional Público y Relaciones Internacionales \\ Universidad de Málaga \\ carolina@uma.es
}

\begin{abstract}
Resumen: El presente artículo pretende discutir las estrategias de resolución del conflicto del Sáhara Occidental puestas en marcha por los diferentes actores participantes en el proceso desde 1975, así como explorar nuevas vías conceptuales y prácticas que puedan conducir a un cambio de óptica en la gestión del mismo. Entre ellas se analizará la posición mantenida por las Naciones Unidas, la naturaleza y sentido del mandato de la MINURSO, la incorporación de Marruecos en la Unión Africana o la condición y papel jugado por el Frente Polisario y, en un sentido más general, la población saharaui.
\end{abstract}

Palabras clave: Sáhara Occidental, proceso de paz, arreglo pacífico de controversias, Naciones Unidas, Unión Africana.

\begin{abstract}
This article aims to discuss the strategies of resolution of the Western Sahara conflict set in motion by the different actors involved in the process since 1975 , as well as to explore new conceptual and practical ways that may lead to a change of perspective in conflict management. These include an analysis of the position of the United Nations, the nature and meaning of the mandate of MINURSO, the incorporation of Morocco into the African Union or the status and role played by the Polisario Front and, in a more general sense, the Saharawi population.
\end{abstract}

Keywords: Western Sahara, peace process, peaceful settlement of disputes, United Nations, African Union.

Sumario: INTRODUCCIÓN. 1. LA POSICIÓN DE LAS NACIONES UNIDAS ANTE EL CONFLICTO DEL SÁHARA OCCIDENTAL: MOLDEANDO LA ARCILLA. 1.1 ¿Negociación? ¿medio de arreglo pacífico adecuado? 1.2. Repensando la naturaleza de la MINURSO: comerse la erre o no pronunciarla. 1.2.1. ¿Un mandato sin sentido ni sensibilidad? 1.2.2. Susto o muerte: ampliación o eliminación de un mandato ineficaz. 1.2.3. Analogías en la posibilidad de administración internacional. 2 EL PAPEL DE LA UNIÓN AFRICANA EN EL PROCESO DE PAZ: DIPLOMACIA INACTIVA Y CÓMO LA MARGARITA DIJO SÍ A MARRUECOS AL FINAL DEL CUENTO. 2.1. La RASD: no sin mi Estado. Los problemas de la bicefalia. 2.2. Aportaciones africanas al proceso de paz. 3. CONCLUSIONES. 4. REFERENCIAS BIBLIOGRÁFICAS.

* El presente estudio se enmarca dentro del proyecto de investigación: «Las Respuestas del Derecho Internacional y Europeo a los Nuevos Riesgos y Amenazas Contra la Seguridad Humana» (RASEGUR), Plan Nacional de I+D+I (Ref., DER2015-65906-P) y del proyecto «Los desafíos de los Derechos Humanos ante los nuevos riesgos y amenazas» (EUIN2017-85437) 


\section{INTRODUCCIÓN}

L os principales órganos de las Naciones Unidas y la doctrina internacionalista han confirmado repetidas veces la ilegalidad de la ocupación marroquí en el territorio del Sáhara Occidental, así como el derecho de libre determinación del pueblo saharaui ${ }^{1}$. Este derecho es, además, una norma de ius cogens $^{2}$, lo que hace que su contenido sea imperativo e imprescriptible 3 . Éste no es flexible ni puede ser violentado por otros sujetos o normas de Derecho Internacional ${ }^{4}$.

No obstante, el Sáhara Occidental sigue siendo la última colonia de África, permaneciendo su inclusión en la lista de Territorios no Autónomos (TNA) de las Naciones Unidas ininterrumpidamente desde $1963^{5} \mathrm{y}$, por tanto, siendo ésta una situación aún transitoria a la espera de que sea aplicado el Derecho Internacional correspondiente (el relativo a la descolonización), que ha sido ya repetidamente declarado.

1 La Asamblea General de las Naciones Unidas comienza a pronunciarse sobre la libre determinación del pueblo saharaui a partir de la Resolución 2072 (XX) de 16 de diciembre de 1965, acogiendo las recomendaciones de una resolución anterior del Comité Especial encargado de la aplicación de la Declaración sobre concesión de la independencia a los países y pueblos coloniales. El Consejo de Seguridad de Organización comienza a examinar la cuestión del Sáhara Occidental en 1975.

2 Para observar la confirmación de la naturaleza de la libre determinación de los pueblos como norma de ius cogens vid. Comentario 3 al art. 50 del Proyecto de artículos de la CDI sobre Responsabilidad Internacional del Estado por hechos ilícitos, en Yearbook of the International Law Commission, 1966, vol. II, pp. 247-249, en http://untreaty.un.org/ilc/texts/instruments/ english/commentaries/1_1_1966.pdf. Vid también el Comentario 5 al art. 26 del Proyecto de la CDI en el Informe de la Comisión de Derecho Internacional, $53^{\circ}$ período de sesiones, Asamblea General, Documentos oficiales, Suplemento n. ${ }^{\circ} 10$ (A/56/10), Naciones Unidas, Nueva York, pp. 216-217. También la Corte Internacional de Justicia en el Asunto de Timor Oriental aduce la obligación de respetar la libre determinación de los pueblos como uno de los principios esenciales del Derecho Internacional: Sentencia de 30 de junio de 1995, Asunto de Timor Oriental (Portugal c. Australia), CIJ Recueil 1995, 102, párrafo 29.

3 Véase, Kolb, R., Théorie du ius cogens international. Essai du relecture du concept, Graduate Institute Publicacions, 2015, pp. 404.

4 Olásolo, H., «La inseguridad jurídica de los acuerdos de paz a la luz del régimen jurídico internacional de los crímenes de ius cogens y la justicia de transición», Politica Criminal, vol. 12, $\mathrm{n}^{\circ} 23,2017$, p. 83, pp. 78-102.

5 En 2017 son un total de 17 territorios los que componen esta lista, siendo el Sáhara Occidental uno de los asuntos que el Comité Especial deberá volver a examinar en 2017. Vid. Período de Sesiones de 2017, Comité Especial Encargado de vigilar la situación con respecto a la aplicación de la Declaración sobre la concesión de la independencia a los países y pueblos coloniales, 9 de diciembre de 2016. A/AC.109/2017/L.2. 
En más de cuarenta años de administración de facto del territorio por un tercer Estado, éste no ha ganado legitimidad en cuando a «reconocimiento» ${ }^{6}$, pero sí ha logrado un estancamiento del conflicto y, con ello, una progresiva asunción de roles propios de la soberanía con la aquiescencia internacional. De esta manera, el conflicto del Sáhara Occidental es un caso de muy compleja puesta en práctica de las normas de Derecho Internacional, lo que puede llevar a su catalogación como un conflicto imposible de resolver (intractable conflict) ${ }^{7}$. Ello queda favorecido por el bloqueo del arreglo pacífico de la controversia desde el alto el fuego de 1991, que ha llevado a una escenario de equiparación falaz de las posiciones mantenidas por ambas partes (Frente Polisario y Marruecos), alimentando la ficción de disputa interna en detrimento del Derecho Internacional y, en particular, de las normas de ius cogens.

Este artículo analizará la gestión del arreglo pacífico de controversias por parte de las dos principales Organizaciones Internacionales relacionadas con el conflicto: Naciones Unidas y la Unión Africana.

\section{LA POSICIÓN DE LAS NACIONES UNIDAS ANTE EL CONFLICTO DEL SÁHARA OCCIDENTAL: MOLDEANDO LA ARCILLA}

\section{- Catalogación jurídica del territorio por el Comité Especial}

Con la aprobación de la Declaración para la concesión de la independencia a los países y pueblos coloniales (Resolución 1514 XV) en $1960^{8}$ y la inclusión en 1963 del Sáhara Occidental en la lista de TNA, éste ha sido considerado por las Naciones Unidas como pendiente de descolonización. A esta consideración subyacen elementos jurídico-internacionales que deben suponer la premisa de partida en la gestión del conflicto. El Derecho Internacional

6 Se observa en este punto un seguimiento estricto por parte de los sujetos de la Comunidad Internacional a la prohibición de no reconocer las adquisiciones territoriales derivadas del uso de la fuerza.

7 BAR-TAL, D., «Societal Beliefs in Times of Intractable Conflict: The Israeli Case», International Fournal of Conflict Management, vol. 9, issue 1, 1998, pp. 22-50; COLEMAN, T., «Intractable Conflict as an attractor: a Dinamical System Approach to Conflict Escalation and Intractability», American Behavioral Scientist, vol. 50, issue 11, 2007, pp. 1454-1475; MAREIKE, P., «The conflict of Western Sahara. The role of the United Nations in resolving it», Term Paper, Otto-von-Guericke University Magdeburg, 2016, pp. 18.

8 Resolución 1514 (XV) de la Asamblea General de las Naciones Unidas, de 14 de diciembre de 1960 . 
impone obligaciones a las potencias administradoras de estos territorios, que se pueden resumir en «procurar la autodeterminación» del mismo, junto con otros apremios como transmitir información sobre la situación, todas ellas derivadas del artículo 73 de la Carta de las Naciones Unidas9. La condición de TNA es, en esencia, un estado jurídico transitorio que no puede ser considerado separadamente al derecho de libre determinación ${ }^{10} \mathrm{y}$ a su naturaleza dinámica, que implica avanzar hacia la plenitud de gobierno propio. Hay que recordar que según la Resolución 1541 (XV) podemos considerar satisfecho el ejercicio de la libre determinación de un TNA cuando el territorio: 1) pasa a ser un Estado independiente y soberano, 2) elije voluntariamente establecer una libre asociación con un tercer Estado o, 3 ) decide (a través de un referéndum o fórmula similar) integrarse en otro Estado independiente.

En el caso que nos concierne no se ha producido el ejercicio del derecho de autodeterminación a través de ninguna de las tres opciones, razón por la cual resulta coherente y apropiada la permanencia del territorio saharaui como TNA. Queda establecida por tanto cual es la condición jurídica del territorio para las Naciones Unidas, así como también la afirmación de los derechos inherentes a la misma (libre determinación de los pueblos). Queda analizar si esta postura de la Organización se ha mantenido en el tiempo o si, por el contrario, ha fluctuado hacia otros enfoques pese a mantener dicha condición formal de TNA. A continuación, se analizará cuál ha sido la línea seguida por la Organización desde las primeras referencias al territorio, comprobando si la gestión del conflicto y su estancamiento se ha podido ver favorecido por la línea adoptada desde el seno de la misma y sus posibles variaciones.

\section{- Asamblea General}

La Asamblea General comenzó a pronunciarse sobre la cuestión del Sáhara Occidental aún en época colonial en 1965, pidiendo «encarecidamente al gobierno de España, como Potencia Administradora, que adopte inmediatamente todas las medidas necesarias para la liberación de los territorios de Ifni y del Sáhara Español

9 Clark, D.; Williamson, R., Self Determination. International Perspectives, Springer, 2016, pp. 443.

10 Las circunstancias especiales de algunos territorios considerados TNA por Naciones Unidas hacen que no sea exigible el cumplimiento del derecho de libre determinación strictu sensu, como en el caso de Gibraltar o las Islas Malvinas, sino que la descolonización habría de producirse por un acuerdo entre los Estados parte en la controversia. 
de la dominación colonial $\gg^{11}$. Un año más tarde, recomendó el envío de observadores $^{12}$. Sin embargo, no fue hasta 1974 cuando se produjo tal expedición (aprobada mediante la misma resolución por la que se solicitaba la emisión del Dictamen Consultivo de la Corte Internacional de Justicia) ${ }^{13}$.

Dicho viaje de inspección al territorio es fundamental para entender la postura que la Organización toma en esta época ante el conflicto. La denominada Misión de Visita de las Naciones Unidas tenía como finalidad informarse acerca de todas las sensibilidades políticas de la población para, posteriormente, recomendar vías de solución al contencioso ${ }^{14}$. Finalmente, se desplazó al territorio en 1975 realizando amplias investigaciones y, extrayendo, varias conclusiones de importancia ${ }^{15}$ : en primer lugar la constatación de que el Frente Polisario era la fuerza política dominante (pese a estar en la clandestinidad y evidenciarse el temor de sus miembros a represalias una vez la Misión de Visita se hubiera marchado) y, además, era un Movimiento de Liberación Nacional $(\mathrm{MLN})$ que la Misión reconocía como el legítimo representante del pueblo saharaui. En segundo lugar instaba a incluir al Frente Polisario y a las demás partes implicadas en la resolución pacífica del conflicto. Esto suponía que, constatada la existencia de un MLN lo incorpora como «parte» en el conflicto. Con ello, la solución pasaba inequívocamente por la aplicación de la Resolución 1514 (XV) en los términos originarios.

\section{- Corte Internacional de fusticia}

Conclusiones muy similares fueron las alcanzadas simultáneamente por el Dictamen Consultivo sobre el Sáhara Occidental de la Corte Internacional

11 Resolución 2072 (XX) de la Asamblea General de las Naciones Unidas, de 16 de diciembre de 1965.

12 Resolución 2229 (XXI) de la Asamblea General de las Naciones Unidas, de 20 de agosto de 1966.

13 Resolución 3292 (XXIX) de la Asamblea General de las Naciones Unidas, de 13 de diciembre de 1974.

14 Vid. Documentos de las Naciones Unidas, A/AC.109/PV.999. Pese a que en un principio la misión se iba a desplegar únicamente en el territorio del Sáhara Español, Marruecos, Mauritania y Argelia pidieron que también se incluyeran sus territorios, además realizó entrevistas con representantes del gobierno franquista en Madrid, por lo que finalmente ésta abarcó un contexto más amplio sobre el conflicto.

15 Informe del Comité Especial encargado de examinar la situación con respecto a la aplicación de la Declaración sobre la concesión de la independencia a los países y pueblos coloniales, volumen III, Documentos de las Naciones Unidas, a/10023, suplemente número 23, 1975. El Informe elaborado por la Misión de Visita se publica los días 13, 14 y 15 de octubre de 1975. Sólo un día después de emitiría el Dictamen Consultivo de la CIJ sobre el Sáhara Occidental. 
de Justicia ${ }^{16}$, pese a la existencia de algunos puntos no suficientemente contundentes ${ }^{17}$. El Dictamen sí era rotundo al afirmar que no se habían constatado líneas jurídicas que pudieran modificar la aplicación de la Resolución 1514 (XV) por lo que se refiere a la descolonización y a la autodeterminación del Sáha$\mathrm{ra}^{18}$. Debido a la extensa literatura sobre esta cuestión no nos detendremos más en el análisis del Dictamen, salvo para hacer referencias futuras al mismo.

\section{- Consejo de Seguridad}

Tras el abandono del territorio por parte de España y la ocupación militar por Marruecos y Mauritania, la postura de las Naciones Unidas frente al conflicto no se había modificado en sus líneas esenciales ${ }^{19}$. Con el estallido del conflicto armado entre Marruecos, el Frente Polisario y Mauritania en 1975, el Consejo de Seguridad comenzó a examinar la cuestión, reafirmando en diversas resoluciones ${ }^{20}$ la aplicación de la Resolución 1514 (XV) en el territorio e instando a Marruecos a que retirara «inmediatamente del territorio del Sáhara Occidental a todos los participantes en la marcha» ${ }^{21}$. Tras el alto el fuego

16 Sahara Occidental, avis consultatif, C.I.J. Recueil 1975. Debido a la extensa atención que la doctrina ha dedicado en diversas ocasiones al análisis del Dictamen Consultivo sobre el Sáhara Occidental este artículo se limita a recordar las líneas clave marcadas por el mismo.

17 Pese a que el pronunciamiento de la Corte Internacional de Justicia parecía desechar la tesis marroquí, del total de las consideraciones con respecto a un supuesto sometimiento de las tribus del Sáhara Occidental al Sultán marroquí, en el Dictamen se llegaba a la siguiente conclusión: «les éléments examinés jusqu'à présent n'établissent aucun lien de souveraineté territoriale entre ce Etat et le Sahara occidental. Ils ne montrent pas que le Maroc ait exercé une activité étatique effective et exclusive au Sahara occidental. Ils indiquent cependant qu'un lien juridique d'allégeance existait pendant le période pertinente entre le Sultan et certains, mais certaines seulement, des populations nomades du territoire». (Sáhara occidental, avis consultatif, C.I.J Recueil 1975, párr. 107). La reacción de éxito marroquí pudo estar basada únicamente en la última línea del párrafo aludido. La expresión, ya casi célebre, «algunas, pero sólo algunas», iba a servir a Marruecos, tan sólo unas horas después de hacerse público el Dictamen, para escudar la venidera Marcha Verde, dirigiéndose el Rey a la nación para asegurar que la Corte había confirmado la marroquinidad del Sáhara Occidental.

18 «La Cour n'a donc pas constaté l'existence de liens juridiques de natura à modifier l'application de la résolution 1514 (XV) quant à la décolonisation du Sahara occidental et en particulier l'application du principe d'autodétermination grâce à l'expression libre et authentique de la volonté des populations du territoire» (Sáhara occidental, avis consultatif, C.I.J Recueil 1975, párr. 162).

19 GonZÁlez Farieta, F. et al., «El papel de la ONU en el conflicto del Sáhara Occidental», Comunicación, Cultura y Política. Revista de Ciencias Sociales, vol. 1, nº 2, 2009, pp. 111-124.

20 Resolución 377 del Consejo de Seguridad de las Naciones Unidas, de 22 de octubre de 1975 y Resolución 379 del Consejo de Seguridad de las Naciones Unidas de 2 de noviembre de 1975.

21 Resolución 380 del Consejo de Seguridad de las Naciones Unidas, de 6 de noviembre de 1975. 
de 1991 después de los esfuerzos realizados por la Organización para lograr la aceptación por las partes del plan de arreglo, el Consejo de Seguridad asume las gestiones de organización y supervisión de un «referéndum de libre determinación del pueblo del Sáhara Occidental», decidiendo establecer a tal efecto la MINURSO22.

Debido a los problemas con el censo y otros incidentes que provocaron la paralización del plan de arreglo ${ }^{23}$, el Consejo de Seguridad comienza a plantearse la posibilidad de establecer una nueva vía de concierto en 1999. Ante las dificultades de la misión para cumplir su objetivo principal (celebración del referéndum) pide al Secretario General que lo mantenga informado «de si el mandato de la MINURSO sigue siendo viable» ${ }^{24}$. En diciembre del mismo año el Consejo de Seguridad «toma nota» sobre las dificultades encontradas por el Secretario General de conciliar a las partes en los puntos controvertidos, pero sigue adelante con la idea de «terminar la identificación de los votantes» ${ }^{25}$. En el año 2000 continua exponiendo su preocupación por el estancamiento del plan de arreglo, lo que no le impide reiterar «su pleno apoyo a los esfuerzos que siguen desplegando el Secretario General, su Enviado Personal, su Representante Especial y la Misión de las Naciones Unidas para el Referéndum del Sáhara Occidental (MINURSO) para la aplicación del plan de arreglo y los acuerdos aprobados por las partes con objeto de celebrar un referéndum libre, justo e imparcial a fin de que el pueblo del Sáhara Occidental pueda ejercer su derecho a la libre determinación ${ }^{26}$. Sin embargo, en esta ocasión incluye la apertura de un período de reflexión con el apoyo al Secretario General en su idea de «pedir a su Enviado Personal que consulte a las partes y que, teniendo en cuenta los obstáculos existentes y posibles, explore medios para lograr una solución pronta, duradera y convenida de la controversia $\gg^{27}$.

En febrero del año 2001, el Consejo prorroga una vez más el mandato de la MINURSO, aludiendo a su deseo de que sean resueltos los problemas que venían dificultando la puesta en marcha del referéndum. Sin embargo,

22 Resolución 690 del Consejo de Seguridad de las Naciones Unidas, de 29 de abril de 1991. MINURSO es el acrónimo de Misión de Naciones Unidas para el Referéndum en el Sáhara Occidental.

23 Soroeta Liceras, J., «El plan de paz del Sáhara Occidental, ¿viaje a ninguna parte?», REEI, $\mathrm{n}^{\circ} 10,2005$, pp. 1-33.

24 Resolución 1235 del Consejo de Seguridad de las Naciones Unidas, de 30 de abril de 1999.

25 Resolución 1282 del Consejo de Seguridad de las Naciones Unidas, de 14 de diciembre de 1999.

26 Resolución 1292 del Consejo de Seguridad de las Naciones Unidas, de 20 de febrero de 2000.

27 Ibidem. 
al mismo tiempo habla de «convenir en una solución política que sea mutuamente aceptable de su controversia respecto del Sábara Occidental» ${ }^{28}$. Esta resolución constituye el impulso progresivo hacia un nuevo tipo de mecanismo de arreglo pacífico, que se asentaría en junio del mismo año cuando el mismo órgano «apoya plenamente los esfuerzos del Secretario General por invitar a todas las partes a reunirse directamente o para celebrar conversaciones indirectas bajo los auspicios de su Enviado Personal, y alienta a las partes a que examinen el proyecto de acuerdo marco y negocien cualesquiera modificaciones concretas que deseen introducir en esta propuesta, y a que examinen cualesquiera otras propuestas para alcanzar una solución política que puedan presentar las partes para llegar a un acuerdo mutuamente aceptable $»^{29}$.

Quedaba, por tanto, abierto, un nuevo proceso de redefinición de las estrategias a seguir, evidenciándose la falta de progresos en la aplicación del plan de arreglo y confirmando que éste era prácticamente inviable en la práctica ${ }^{30}$. El Consejo de Seguridad, siempre siguiendo las recomendaciones del Enviado Especial, abre aquí la puerta al recurso a la negociación de las partes que podría llegar a establecer nuevas pautas de solución al conflicto, sin embargo, no se explica jurídicamente cuáles serían los fines de esas nuevas estrategias y su posible incidencia en el respeto del derecho de autodeterminación como norma de ius cogens.

Los problemas en la aplicación del plan de arreglo, en especial, la imposibilidad de finalizar la elaboración del censo de votantes para el referéndum, acaba por dinamitar la efectiva celebración del mismo. Con ello, la gestión del conflicto por parte del Consejo de Seguridad sufre una transición muy relevante: de la apuesta por una solución jurídica dentro del artículo 73 de la Carta (plan de arreglo y referéndum), se opta ahora por acoger la posibilidad de una solución política. Esto supone la falta de seguimiento al marco jurídico determinado por la Carta y su derecho derivado para el ejercicio del derecho de autodeterminación y la apuesta por el posibilismo. De esta opción derivaría una determinada elección de medios de arreglo pacífico: la negociación.

La apertura de la vía de la negociación queda consagrada en el año 2007, período en el que ya el Consejo de Seguridad sólo menciona la MINURSO en su función de vigilancia del alto el fuego y, donde además «exhorta a las partes a

28 Resolución 1341 del Consejo de Seguridad de las Naciones Unidas, de 27 de febrero de 2001.

29 Resolución 1359 del Consejo de Seguridad de las Naciones Unidas, de 29 de junio de 2001.

30 Soroeta Liceras, J., «El conflicto del Sáhara Occidental en el contexto del nuevo orden internacional», Revista Española de Derecho Internacional, 54, nº 1, 2002, pp. 491-497. 
que entablen negociaciones de buena fe sin condiciones previas ${ }^{31}$, teniendo presentes los acontecimientos de los últimos meses, con miras a lograr una solución politica justa, duradera y mutuamente aceptable que conduzca a la libre determinación del pueblo del Sábara Occidental» ${ }^{32}$, pidiendo al Secretario General que convoque dichas negociaciones bajo sus auspicios.

\section{1. ¿Negociación? ¿medio de arreglo pacífico adecuado?}

Los buenos oficios ejercidos por la Organización de Naciones Unidas en forma de resoluciones del Consejo de Seguridad en el año 2007, en concreto de la 1754 (2007), llevan al llamado proceso de negociación de Manhasset ${ }^{33}$. El mismo nace con una inquietud jurídico-internacional evidente, ya que su naturaleza puede entrar en confrontación directa con el respeto del principio de autodeterminación y con la Resolución 1514 (XV) de la Asamblea General de las Naciones Unidas. No resulta nuevo el hecho de que un proceso de paz pueda generar inseguridad jurídica por su falta de respeto a las normas de ius $\operatorname{cogens}^{34}$. En este sentido, la consecuente vulneración de la libre determinación, implicaría la negación del ejercicio de un derecho a un sujeto de Derecho Internacional. Porque los pueblos tienen subjetividad internacional (limitada) en el Derecho Internacional, en estrecha conexión con este preciso derecho ${ }^{35}$.

Comenzar un proceso de negociación sobre esta base trae aparejados algunos vicios. De hecho, después de la celebración de cuatro rondas de negociación (Manhasset I, II, III y IV), no hubo progresos significativos en la solución del contencioso saharaui, pese a la participación en todas ellas de las delegaciones de las partes del conflicto y el auspicio de las Naciones Unidas. Por ello, este proceso tuvo en 2009 un cambio de enfoque impulsado por el que fuera reelegido como Enviado Especial, Christopher Ross ${ }^{36}$. Pese a este

31 Negrita de la autora: se evidencia aquí que la solución política no parece tener que incluir como condición previa, según el Consejo de Seguridad, el respeto a las normas de Derecho Internacional.

32 Resolución 1754 del Consejo de Seguridad de las Naciones Unidas, de 30 de abril de 2007.

33 Manhasset en una pequeña ciudad cercana a Nueva York elegida como marco neutral de las negociaciones entre el Frente Polisario y Marruecos.

34 Olásolo, H., «La inseguridad jurídica de los acuerdos de paz...», op. cit.

35 BARSH, R. L., «Indigenous People in the 1990s: from object to subject of International Law?», Harvard Human Rights Fournal, 7, 1994.

36 https://elpais.com/internacional/2009/01/07/actualidad/1231282811_850215.html. 
movimiento diplomático de último lastre, en 2010, 2011 y 2012 los resultados de las conversaciones fueron prácticamente los mismos, tan solo habiendo logrado conciliar a las partes en detalles secundarios que no incidían en el fondo de la cuestión, como la coordinación de éstas para la limpieza de minas antipersonales en el territorio bajo control del Frente Polisario.

Estos episodios de negociaciones sobre cuestiones auxiliares al proceso de paz han terminado por perpetuar aún más el estancamiento de la cuestión del Sáhara Occidental ${ }^{37}$, acrecentado todo ello con las posiciones de las partes, cada vez más irreconciliables en cada una de las sesiones ${ }^{38}$. Por un lado, el Frente Polisario seguía clamando por un referéndum de autodeterminación que incluyera la opción de la independencia, por otro, Marruecos continuaba ofreciendo una autonomía limitada dentro de su territorio ${ }^{39}$, con la celebración de un referéndum que incluyera sólo dos opciones: la plena integración en el Reino de Marruecos o la concesión de un estatuto de autonomía para el territorio.

Hay que recordar que la negociación como medio de arreglo pacífico tiene límites e incluso requisitos. El Derecho Internacional ha insistido en la necesidad de que exista «buena fe» en los procesos de negociación, y la falta de voluntad de entendimiento podría entenderse como un supuesto de responsabilidad internacional. La Corte Internacional de Justicia, en el asunto de las Plataformas Continentales en el Mar del Norte señaló que: «The Parties were under an obligation to enter into negotiations with a view to arriving at an agreement and not merely to go through a formal process of negotiation as a sort of prior condition for the automatic application of a certain method of delimitation in the absence of agreement; they were so to conduct themselves that the negotiations were meaningfu ${ }^{\star 40}$. Igualmente, la Declaración de Manila sobre el arreglo pacífico de controversias internacionales ${ }^{41}$ insiste en la necesidad de

37 Glozman, E. et al., «False Negotiations. The Art and Science of Not Reaching an Agreement», Fournal of Conflict Resolution, vol. 59, Issue 4, 2015, pp. 671-697.

38 Report of the Secretary-General on the situation concerning Western Sahara, 19 April 2016, S/2016/355.

39 Ruiz Miguel, C., «La propuesta marroquí de autonomía para el Sáhara de 2007: una antigua propuesta sin credibilidad», REAF, $\mathrm{n}^{\circ} 7$, octubre, 2008, pp. 268-291.

40 Summary of the Summary of the Judgment of 20 February 1969, NorTh SEa Continental SHELF CASES, Judgment of 20 February 1969.

41 Declaración de Manila sobre el arreglo pacífico de controversias internacionales, aprobada por la Resolución 36/10 de la Asamblea General de las Naciones Unidas de 15 de noviembre de 1982. 
obrar de buena fe y con espíritu de cooperación al tiempo que establece que como primordial que las negociaciones se den de manera efectiva.

En el informe del año 2016 del Secretario General sobre el Sáhara Occidental, éste expresó igualmente su preocupación por el rumbo de las negociaciones y la falta de voluntad de las partes, lamentando «la ausencia de unas verdaderas negociaciones sin condiciones previas y de buena fe para lograr una solución política mutuamente aceptable, que prevea la libre determinación del pueblo del Sáhara Occidental». Añadiendo además que «las partes seguían sin acercar posiciones, que se mantenían mutuamente excluyentes, y ninguna de las partes había logrado convencer a la otra de las ventajas de su propuesta y así avanzar hacia una solución $\gg^{42}$. Las negociaciones de Manhasset no han estado en concordancia con estos principios del Derecho Internacional ni con las recomendaciones del Secretario General debido a la ausencia de sentido en cuanto al objetivo principal del proceso de paz y la ausencia de buena fé y cooperación entre las partes.

Las estrategias de arreglo pacífico de la controversia caían en un brete con la marcha en 1975 de España de territorio, lo que interrumpía la descolonización con la ruptura del derecho de autodeterminación mediante los acuerdos de Madrid ${ }^{43}$. Acuerdos que eran inválidos desde el punto de vista del Derecho Internacional, contraviniendo varios preceptos de la Convención de Viena sobre el Derecho de los Tratados como el 53 o el $80^{44}$. Así, tras la frustración del plan de arreglo ya señalado, no podemos considerar que este conflicto esté en la actualidad regulado por ningún acuerdo de paz salvo

42 Informe del Secretario General sobre la situación relativa al Sáhara Occidental, 19 de abril de 2016, S/2016/355, párr. 9 y párr. 17.

43 Declaración de principios entre España, Marruecos y Mauritania sobre el Sáhara Occidental de 14 de noviembre de 1975. Firmado por Carlos Arias Navarro, Ahmed Osman y Hamdi Mouknass, no publicado en el B.O.E, sí en la ONU años después de su conclusión: vid. United Nations Treaty Series, vol. 988, I, n 14450 . Los denominados «acuerdos tripartitos de Madrid» tuvieron lugar entre España, Marruecos y Mauritania con la intención de obviar el proceso descolonizador en el Sáhara occidental y optar por otro desenlace atípico: la metrópoli entregaba el territorio a los dos países con pretensiones anexionistas el territorio de la colonia sin tener en cuenta la opinión de la población saharaui. En él destaca que no aparezca como parte firmante del mismo ningún representante del pueblo saharaui, y que no se mencione la petición, hecha y reiterada por la Asamblea General en distintas Resoluciones, de promover la celebración de un referéndum de autodeterminación en el que se garantice que sea el pueblo autóctono el que tome la decisión sobre su futuro.

44 El artículo 53 se refiere a la nulidad de los Tratados que están en oposición con una norma imperativa de derecho internacional general («jus cogens») y el artículo 80 a la obligación de registro y publicación de los mismos. 
los acuerdos militares sobre las condiciones concretas del alto el fuego. Este hecho resulta de especial trascendencia por la inseguridad jurídica que se ha evidenciado en el proceso. Se da, así, la circunstancia de que existen dos partes de un conflicto inmersas en un proceso de paz sin ningún acuerdo que regule efectivamente el proceso. La vía política carece de márgenes, puntos, fases o estadios a cumplir y la vía jurídica no es tomada en consideración por Naciones Unidas en su labor de buena oficiante y mediadora del conflicto. En una vía política de negociación sobre derechos pretendidamente blindados (libre determinación de los pueblos) sin regulación mínima y sin asunciones previas, las Organizaciones Internacionales deben ser cautelosas con el respeto de las normas imperativas y del derecho internacional consuetudinario ${ }^{45}$. Hay que recordar que las normas de ius cogens son un límite a todos los medios de arreglo pacífico, incluida la negociación.

No obstante, según el Informe del Secretario General de 2016, el Ministro Delegado de Asuntos Exteriores Marroquí declaró que las bases del proceso de negociación debían seguir siendo la búsqueda de «una solución política que no cuestionara el estatuto del Sábara Occidental, en la medida en que «el Sábara ya es marroqui» ${ }^{46}$. Ante esta disparidad de planteamientos diplomáticos, y teniendo en cuenta que el cometido principal del plan de arreglo de 1991 se frustró hace años (la celebración de un referéndum de autodeterminación), ¿cómo es posible que se establezca un marco institucional y estructural para un proceso de negociaciones en el que las partes no han renovado las bases de un acuerdo de pa $^{47}$ e indicado, al menos, los puntos a debatir y sobre los que convenir?

Por otro lado, el nuevo Secretario General Gutérres ha revitalizado el papel de Naciones Unidas como mediadora del conflicto, ya que pretende ofrecer un nuevo impulso a las negociaciones, consciente de estas mismas carencias. Como afirma en su Informe sobre la situación en el Sáhara Occidental de 2017 «tengo la intención de proponer que se reanude el proceso de negociación con una nueva dinámica y un nuevo espiritu que reflejen las orientaciones del Consejo, con el fin de llegar a una solución politica mutuamente aceptable que incluya la solución de la controversia sobre el estatuto jurídico del Sáhara Occidental, en particular median-

45 Sobre este extremo vid., ZARTAMn, I. W., «Conflict Resolution and Negotiation», en The Sage Handbook of Conflict Resolution (Bercowith et al. [eds.]), Londres, SAGE, 2009, pp. 322-340, pp. 682.

46 Informe del Secretario General sobre la situación relativa al Sáhara Occidental, 19 de abril de 2016, S/2016/355, párr. 20.

47 Massé, F., «Negociaciones de paz y causa de los conflictos», Ultimátum, Revista Zero, p. 50-55. 
te un acuerdo sobre la naturaleza y la forma del ejercicio de la libre determinación» ${ }^{48}$. El nuevo impulso y espíritu que quiere dar el Secretario General al proceso de negociación parece implicar la toma de algunas decisiones transcendentes, que serán necesarias para que el nuevo enfoque prospere. Como anuncia en el citado Informe «si no se adoptan esas decisiones, habrá que extraer las conclusiones pertinentes». Así, En la Resolución 2414 (2018) del Consejo de Seguridad, éste exhorta a las partes «a que den muestras de voluntad politica y trabajen en una atmósfera propicia para el diálogo a fin de reanudar las negociaciones», lo que hace suyo el Secretario General en su Informe de 2018 en el que pide a las mayor un compromiso con el proceso de negociación ${ }^{49}$. Afirma, además, que «el proceso de negociación no se produce de la nada» y pide mayor implicación a los Estados vecinos ${ }^{50}$.

En otro orden de cosas, hay que subrayar otro elemento que socava el buen ritmo de las negociaciones marroquí-saharauis: la ausencia de inclusión de una perspectiva de género en las mismas, tal y como reclama la Resolución 1325 (2000) del Consejo de Seguridad, y como sería deseable de cualquier proceso de paz que tenga lugar tras el año 2000. Como se ha expresado en repetidas ocasiones, existen dudas razonables de legitimidad en un acuerdo de paz en el que la participación de las mujeres sea inexistente o demasiado limi$\operatorname{tada}^{51}$. El empoderamiento de las mujeres en la etapa pos conflictual se vuelve extremadamente complejo si el proceso de reconstrucción de las sociedades en conflicto se lleva a cabo sin la participación de éstas. Ni el Frente Polisario y ni Marruecos han incluido de hecho a ninguna mujer en las diferentes rondas del proceso de Manhasset (I, II, III o IV). A ello hay que sumar que tampoco estaban presentes en las delegaciones de ninguno de los demás participantes en el proceso (Argelia, Mauritania o Naciones Unidas), lo que supone un gran falta de democracia participativa y contraviene el sentido de las resoluciones del programa «la mujer, la paz y la seguridad» del Consejo de Seguridad de las Naciones Unidas. En el mismo escenario hay que situar a la MINURSO, que cuenta con sólo 14 mujeres de un total de 244 efectivos $^{52}$. No obstante, hay

48 Informe del Secretario General sobre la situación en el Sáhara Occidental, 10 de abril de 2017, S/2017/307, párr. 83.

49 Informe del Secretario General sobre la situación relativa al Sáhara Occidental, 29 de marzo de 2018, S/2018/277, párr. 78

50 Ibid., párr. 79.

51 (Bell et al., 948).

52 Informe del Secretario General sobre la situación relativa al Sáhara Occidental, 29 de marzo de 2018, S/2018/277, párr. 32. 
que destacar el papel de la canadiense Kim Bolduc quien, además de ser la Jefa de la Misión, en 2017 era nombrada Enviada Especial del Secretario General para el Sáhara Occidental.

Tanto esta como otras cuestiones deben plantearse en el nuevo enfoque del proceso de paz, reflejando la incorporación de mujeres en el mismo ${ }^{53} \mathrm{y}$ reconsiderando la carencia de un marco idóneo para llevar a cabo las conversaciones $^{54}$, así como el cumplimiento del Derecho Internacional consuetudinario y el respecto a sus normas imperativas.

Todo ello si se defiende que el modo idóneo que avanzar en el proceso de paz es a través de la negociación. No siendo así desde mi punto de vista, hay que señalar la existencia de muchas otras vías de solución pacífica de conflictos que van más allá de la negociación directa. Es cierto que el Derecho Internacional ha previsto «el recurso preferente a la negociación $»^{55}$ pero esto no debe suponer una repetitiva moratoria automática si el proceso está siendo infructuoso. Es más, las partes en una controversia internacional tienen la obligación que recurrir a otros procedimientos de arreglo si la negociación se ha agotado por ausencia de buena fe y falta de resultados, responsabilidad que también concierne al Consejo de Seguridad en virtud del artículo 36 de la Carta.

Incluso se puede admitir que la negociación pueda coexistir con otros medios de arreglo de manera simultánea, como ha confirmado la Corte Internacional de Justicia en el asunto relativo al personal diplomático y consular de Estados Unidos en Teherán y en el asunto de las actividades militares y paramilitares en y contra Nicaragua, pero no que por sí sola sea un medio capaz de conseguir un avance real en un proceso que dura ya más de cuarenta años. Lo que lamentablemente ha facilitado su posible catalogación como intractable conflict.

Más aún con la reciente crisis en la zona de Guerguerat que ha supuesto acusaciones cruzadas de Frente Polisario y Marruecos de ruptura del alto el fuego en varias ocasiones con el posicionamiento de componentes militares de ambas partes en esa área neutral, lo que ha provocado que el Secretario General les alentara a mantener el statu quo del territorio. Pese a ello Marruecos insistía en continuar con su presencia en el Guerguerat hasta terminar la carre-

53 Shea, P. E; Christian, C., «The Impact of Women Legislators on Humanitarian Military Interventions», Fournal of Conflict Resolution, vol. 61, issue 10, 2017, pp. 2.43-2073.

54 Rice, P., «The Finite Negotiation Problem. A Solution Theory», fournal of Conflict Resolution, vol. 23, issue 3, 1979, pp. 561-576.

55 Rogoff, M. A., «The Obligation to Negotiate in International Law. Rules and Realities», Michigan fournal of International Law, vol. 16, issue 1, 1994, pp. 141-186. 
tera, que había sido el germen de la controversia y el Polisario imponía como una de sus condiciones que hubiera avances en el proceso de paz y, además, que la MINURSO volviera a funcionar con plena capacidad ${ }^{56}$, lo que sucedía finalmente la segunda quincena de abril de $2017^{57}$.

No obstante, el problema parece lejos de solucionarse teniendo en cuenta que la Resolución 2414 (2018) del Consejo de Seguridad «expresa preocupación por la presencia del Frente Polisario en la zona de separación en Guerguerat y pide su retirada inmediata» además de reconocer que «siguen pendientes cuestiones fundamentales relacionadas con el alto el fuego ${ }^{58}$. Aún con estas recientes dificultades, en junio de 2016 el Enviado Especial del Secretario General para el Sáhara Occidental, Christopher Ross, comenzaba las consultas para la reanudación del proceso de negociación ${ }^{59}$, que finalmente llegaría a ninguna parte salvo a su propia dimisión en enero de 2017.

El nuevo enviado especial del Secretario General, Horst Kohler continuaba con la idea de dar un impulso nuevo al proceso de negociación sin sacrificar con ello los principios fundamentales asentados en el mismo, afirmado que «no action should be taken, which may constitute a change to the status $q u »^{60}$. Queda esperar para analizar los avances que puedan traer estas nuevas premisas.

\subsection{Repensando la naturaleza de la MINURSO: comerse la erre o no pronunciarla}

Otra de las variables del conflicto es la operación de mantenimiento de la paz enviada al territorio en 1991. La MINURSO (Misión de Naciones Unidas para el Referéndum del Sáhara Occidental) fue establecida por la citada resolución 690 del Consejo de Seguridad en dicho año ${ }^{61}$, junto con el alto el fuego y el plan de arreglo. El objetivo principal de esta misión era preparar

56 Informe del Secretario General sobre la situación en el Sáhara Occidental, 10 de abril de 2017, S/2017/307, párrs. 1-12.

57 Informe del Secretario General sobre la situación relativa al Sáhara Occidental, 29 de marzo de 2018, S/2018/277, párr.. 47.

58 Resolución 2414 del Consejo de Seguridad de las Naciones Unidas, de 27 de abril de 2018.

59 Ibid., párr. 23.

60 Statement attributable to the Spokesman for the Secretary-General on Western Sahara [scroll down for French], 19 May 2017. Accesible en: https://www.un.org/sg/en/content/sg/statement/2018-05-19/statement-attributable-spokesman-secretary-general-western-sahara.

61 Resolución 690 del Consejo de Seguridad de las Naciones Unidas, de 29 de abril de 1991. 
el territorio para la celebración de un referéndum de autodeterminación, con la colaboración de la Unión Africana (entonces por la Organización para la Unidad Africana). Tanto Marruecos como el Frente Polisario fueron llamados a cooperar plenamente con el objetivo de la misión, ya que ambos habían accedido previamente a la celebración de la consulta.

Después de un periodo de 6 semanas, la MINURSO estaba preparada para empezar su plan: organizar el referéndum de autodeterminación en el que se podrían votar dos opciones: independencia del Sáhara Occidental o integración en el Reino de Marruecos. Hay que señalar la gran expectación levantada por el mandato de la MINURSO. Era la primera OMP (y hasta el momento la única) que tenía entre sus funciones la celebración de una consulta de estas características. También era muy nítida la línea que ésta debía seguir, en concordancia con el plan de arreglo y sus diferentes estadios ${ }^{62}$. Sin embargo, ya que el referéndum nunca tuvo lugar (por los obstáculos antes mencionados), el mandato de la MINURSO resultó ser ineficaz y el resultado del mismo infructuoso.

Después de que se frustrara el referéndum, el mandato de la MINURSO se ha reducido en la práctica ${ }^{63}$ a las siguientes tareas: vigilar el alto el fuego, reducir la amenaza que suponen las minas no explotadas y apoyar las medidas de aumento de la confianza entre las partes. Formalmente, el mandato no ha sido modificado aunque estas son las funciones que vienen explicitadas en su página web.

De hecho, existe cierta divergencia en la manera en la que las partes entienden el mandato actual de la MINURSO. Así lo advierte el Secretario General en su Informe de 2018 cuando advierte que «el problema más importante al que se enfrenta el funcionamiento de la misión sigue siendo las interpretaciones divergentes que las partes dan al mandato ${ }^{64}$. Ya en su Informe de 2017 el Secretario General reconocía que Marruecos considera que sus funciones se limitan a «supervisar el alto el fuego, apoyar la remoción de minas y prestar asistencia a la Oficina del Alto Comisionado de las Naciones Unidas para los Refugiados (ACNUR) en sus actividades de fomento de la confianza

62 Solá Martín, A., «The Contribution of Critical Theory to New Thinking on Peacekeeping. Some Lessons from MINURSO», Working Paper 15, University of Bradford, 2015, pp. 18.

63 Informe del Secretario General sobre la situación en el Sáhara Occidental, 10 de abril de 2017, S/2017/307, párr. 55 .

64 Informe del Secretario General sobre la situación relativa al Sáhara Occidental, 29 de marzo de 2018, S/2018/277, párr. 52. 
en caso de que estas se reanuden tras su interrupción en julio de 2014, pero no incluye contactos con la sociedad civil u otras entidades civiles. En cambio, en opinión del Frente Polisario el elemento central del mandato de la Misión es organizar un referéndum de libre determinación, y la supervisión del alto el fuego y demás actividades están subordinadas o contribuyen a ese objetivo».

Con respecto al primer punto, es cierto que la misión debe controlar cada vez más las diferentes denuncias de ruptura de alto el fuego de ambas partes, tras la crisis de Guerguerat, por lo que el peso de sus actividades se concentra en este extremo de verificación. Sin embargo, en cuanto a las medidas de aumento de la confianza entre las partes, hay que notar que éstas llevan interrumpidas desde junio de 2014, por lo que es una función en suspenso ${ }^{65}$.

El resultado de esta transformación es que actualmente la MINURSO, no solo tiene un mandato insuficiente sino incoherente, contribuyendo así al mantenimiento de una situación «ni de paz ni de guerra» que lleva únicamente a la frustración de ambos pueblos. El mandato original no ha sido modificado formalmente, por lo que el Frente Polisario está en su derecho de reclamar el cumplimiento de las funciones pertinentes. Sin embargo, la realidad práctica de la MINURSO es que hace años sólo ha llevado a cabo los tres puntos señalados anteriormente, y sobre los que Marruecos no está dispuesto a debatir.

\subsection{1. ¿Un mandato sin sentido ni sensibilidad?}

El mandato actual de la misión carece a su vez de control alguno sobre las violaciones de Derechos Humanos que se dan en el territorio. La Resolución 2218 del Consejo de Seguridad ponía sobre la mesa la cuestión en el año 2015, reflexionando sobre el estado de los Derechos Humanos en la zona y «alentando a las partes a que prosigan sus esfuerzos respectivos por mejorar la promoción y protección de los derechos humanos en el Sáhara Occidental y en los campamentos de refugiados de Tinduf, entre ellos la libertad de expresión y la de asociación» ${ }^{66}$. La resolución favorece una visión equidistante de la protección de Derechos Humanos al uno y otro lado del muro que separa a la población saharaui. Sin embargo, en los campamentos de refugiados de Tindouf existe, en palabras del Secretario General, una «relativa tranquilidad ${ }^{67} \mathrm{y}$, mientras que lo que ocurre

65 Ibid., párr. 64.

66 Resolución 2218 del Consejo de Seguridad de las Naciones Unidas, de 29 de abril de 2016.

67 Informe del Secretario General sobre la situación en el Sáhara Occidental, 10 de abril de 2017, $\mathrm{S} / 2017 / 307$. 
en el territorio del Sáhara Occidental parece altamente preocupante: casos de desapariciones, torturas, detenciones ilegales, presos políticos ${ }^{68}$ y juicios sin garantías suficientes que debe analizarse separadamente ${ }^{69}$, por la extrema vulnerabilidad de una población de sentimientos nacionalistas muy marcados, que son administrados por el Reino de Marruecos. En este sentido, la situación de desprotección de la población saharaui en el territorio del Sáhara Occidental puede asimilarse jurídicamente a la de los desplazados internos, sin que éstos se hayan desplazado de su propio territorio, ya que no cuentan con la protección de ningún Estado pero sufren persecución por la defensa de la autodeterminación del pueblo saharaui, sin que tengan la posibilidad de salir del territorio.

La preocupante situación de los Derechos Humanos que tiene lugar en el Sáhara Occidental es similar a otros territorios cuya OMP incluye en su mandato la vigilancia de los Derechos Humanos ${ }^{70}$. Sin embargo, el mandato de la MINURSO aún no ha sido modificado formalmente desde su despliegue, pese a los cambios fundamentales experimentados en sus circunstancias, como la frustración del referéndum o las importantes denuncias de violaciones de Derechos Humanos.

No obstante, las violaciones están siendo consideradas en alguna medida por el Procedimiento Especial del Consejo de Derechos Humanos de la ONU. En su último informe, el experto independiente de derechos humanos y solidaridad internacional en su misión a Marruecos incluyó como recomendación «to develop one buman-rights-sensitive national framework policy on buman

68 Vid. Entre otras fuentes: Los derechos humanos en el Sáhara Occidental y los campos de refugiados de Tindouf, Human Rights Watch, 2008, accesible en: https://www.hrw.org/sites/default/files/reports/wsahara1208spsumandrecs.pdf; Los Derechos Humanos en Marruecos y el Sáhara Occidental, Amnistía Internacional, accesible en: https://www.es.amnesty.org/en-queestamos/paises/pais/show/marruecos-y-el-sahara-occidental/.

69 El último ejemplo de ello son los llamados juicios de Gdeim Izik, que concluyeron en el Tribunal de Apelaciones de Marruecos el pasado 17 de julio de 2017 con la condena de 23 activistas saharauis a penas entre dos años de cárcel y cadenas perpetuas, por haber participado en la instalación de un campamento pacífico en la localidad de Gdeim Izik reclamando el derecho de autodeterminación del pueblo saharaui. Las acciones del grupo de Gdeim Izik han sido consideradas por muchos como el inicio de la primavera árabe, vid., entre otros: SzMOLKA, I., «El conflicto del Sáhara Occidental en el marco de la primavera árabe», Revista de Investigaciones Politicas y Sociológicas, vol. 12, nº 2, 2013, pp. 45-64.

70 Entre las OMP actuales que incluyen los Derechos Humanos como parte de su mandato podemos señalar a MINUSCA, UNMIL, MONUSCO, MINUSTAH, MINUSMA, UNMISS, UNMIK o UNAMID. 
development $\gg^{71}$. Al mismo tiempo la visita del Subcomité para la Prevención de la Tortura y Otros Tratos o Penas Crueles, Inhumanos o Degradantes evaluó en 2017 el trato dispensado a las personas privadas de libertad y recomendó a Marruecos la creación de un órgano nacional de supervisión, sin que por el momento se haya establecido.

Actualmente, el Procedimiento Especial del Consejo de Derechos $\mathrm{Hu}-$ manos de las Naciones Unidas es el único mecanismo de protección de Derechos Humanos que se encuentra controlando de manera sistemática estas violaciones en Marruecos en general. El objetivo de este procedimiento es identificar los problemas más graves de protección de Derechos Humanos en un territorio en concreto, dada su naturaleza de examen al «Estado-Nación», en este caso, Marruecos (véase por ejemplo las alegadas violaciones de Derechos Humanos en el RIF y otras zonas del Estado marroquí), pero quedaría fuera de la competencia de este procedimiento poner el foco de atención en una problemática específica ${ }^{72}$ de un TNA, como la de la población saharaui. Por esta misma razón, esta herramienta no es lo suficientemente comprehensiva de una análisis a largo plazo que pudiera llevar a entender la dimensión particularísima de la población que vive bajo la administración de un tercer Estado que niega sus diferentes sentimientos nacionalistas, étnicos, políticos o su manera de entender las relaciones de género o la religión. Prueba de ello es que el Procedimiento Especial no se ha ocupado durante el siguiente período de examinar la zona, por lo que esta labor de vigilancia no la ha realizado organismo alguno $^{73}$.

Otra cuestión diferente es si este mecanismo es el adecuado para vigilar los derechos humanos en el contexto del Sáhara Occidental o, en su lugar, lo sería la MINURSO. Hay que tener en cuenta que la mayoría de OMP multidimensionales ${ }^{74}$ incluye en su mandato un enfoque de Derechos Humanos y

71 Report of the Independent Expert on human rights and international solidarity on her mission to Morocco, Human Rights Council Thirty-second session Agenda item 3 Promotion and protection of all human rights, civil, political, economic, social and cultural rights, including the right to development, 27 April 2016, A/HRC/32/43/Add.1.

72 Gifra Dural, J., «La reforma de los procedimientos especiales del Consejo de Derechos Humanos: ¿una mejora en los mecanismos extra convencionales?», Anuario de Derechos Humanos. Nueva Época, vol. 3, 2009, pp. 223-259.

73 Informe del Secretario General sobre la situación en el Sáhara Occidental, 10 de abril de 2017, S/2017/307, párr. 68.

74 Las Operaciones de Mantenimiento de la Paz multidimensionales o de tercera generación siguen la doctrina Capstone, cuyos principios y guías venían establecidos en 2008 por un Documento del Departamento de Operaciones de Paz de Naciones Unidas que consideraba necesario 
un equipo especializado. Estas OMP integradas llevan a la práctica el enfoque que vincula la paz y la seguridad con los Derechos Humanos, cuestión que no se tenía en cuenta en los mandatos más antiguos, y que sigue sin incluirse en las renovaciones de misiones como $\mathrm{UNMOGIP}^{75}$ o $_{\text {FNUOS }}{ }^{76}$ que, junto con la MINURSO, son de las pocas que no han sido reconducidas bajo esta multidimensionalidad.

En el resto de OMP, el Consejo de Derechos Humanos participa como órgano asesor en el desarrollo de este enfoque de derechos humanos. El Secretario General de las Naciones Unidas en su Informe sobre el Sáhara Occidental de 2016 ya aseguraba que la «aplicación efectiva del mandato de la MINURSO exige que la Misión pueda desempeñar todo el rango de funciones habituales de mantenimiento de la paz que las operaciones de las Naciones Unidas realizan en todo el mundo» ${ }^{77}$. Por este motivo, el escueto mandato de la MINURSO y su alejamiento de la problemas que enfrenta la población en el territorio constituyen una excepción a la manera de enfocar el diseño de los mandatos en las OMP actuales, lo que pone en entredicho incluso su permanencia en la zona.

Respecto a otros órganos de protección de Derechos humanos hay que afirmar que la Oficina del Alto Comisionado de las Naciones Unidas para los Derechos Humanos continúa planificando una misión de seguimiento para el territorio, tras sus visitas en 2015 y 2016, pero hasta el momento no se ha producido tal despliegue. Por otro lado, se esperaba la visita del Relator Especial sobre la tortura y los tratos o penas inhumanos o degradantes para 2015, sin que se haya producido hasta el momento, salvo el despliegue anteriormente comentado del Subcomité.

A nivel interno, venía existiendo cierta comunicación entre la MINURSO y el Consejo Nacional de Derechos Humanos de Marruecos, que finalmente ha sido interrumpido desde marzo de $2016^{78}$. Esto deja la vigilancia

prestar atención a cuatro conceptos: peacekeeping, peace enforcement, peace-making y conflict prevention. United Nations Peacekeeping Operations. Principles and Guidelines. Department of Peacekeeping Operations \& Department of Field Support. Marzo, 2008. http://pbpu.unlb. org/pbps/Library/Capstone_Doctrine_ENG.pdf.

75 Grupo de Observadores Militares de Naciones Unidas en la India y Pakistán. Creada en 1949 para vigilar la cesación del fuego en Jammu y Cachemira.

76 Fuerza de las Naciones Unidas de Observancia y Separación. Creada en 1974 para vigilar en alto el fuego entre Israel y Siria.

77 Informe del Secretario General sobre la situación relativa al Sáhara Occidental, 19 de abril de 2016, S/2016/355, párr. 51.

78 Informe del Secretario General sobre la situación en el Sáhara Occidental, 10 de abril de 2017, S/2017/307, párr. 56. 
y protección de los Derechos Humanos en el territorio sin la colaboración periódica de ningún organismo internacional. Como afirma el Secretario General en su Informe de 2017 «la falta de rendición de cuentas por estas y otras violaciones de los derechos humanos contra los habitantes del Sáhara Occidental, así como la persistente falta de investigación de las denuncias de violaciones de ese tipo, fueron importantes motivos de preocupación durante el período sobre el que se informa» ${ }^{79}$.

1.2.2. Susto o muerte: ampliación o eliminación de un mandato ineficaz

En la situación actual de avivamiento del conflicto parece claro afirmar que el mandato de la MINURSO es incoherente y necesita ser reformulado, ampliando sus funciones en concordancia con las necesidades del proceso de paz.

Después de los incidentes del 16 de marzo de 2016 cuando Marruecos decidió expulsar a 84 miembros del componente civil de la misión y de la Unión Africana, el rol que juega la MINURSO en el proceso de paz es incierto y débil. Esta fragilidad se ponía de manifiesto en la Resolución 2285 (2016) del Consejo de Seguridad, en la que se pedía al Secretario General que proporcionara información sobre la situación de la MINURSO después de un plazo de 90 días que Naciones Unidas ofreció a Marruecos para reintegrar al personal afectado por la expulsión. Después de ese plazo, la resolución esperaba que la MINURSO recuperara «full functionality and expresses its intention, if MINURSO bas not achieved full functionality, to consider bow best to facilitate achievement of this goal ${ }^{80}$ al mismo tiempo que prorrogaba (lo que quedaba de) la misión hasta abril de 2017. Según el Informe del Secretario General sobre el Sáhara Occidental de 2017, tras ese plazo de 90 días la MINURSO no pudo volver a funcionar con su plena capacidad ${ }^{81}$, admitiendo Marruecos únicamente el regreso de 25 de los funcionarios internacionales expulsados. Finalmente la misión volvía a contar con todo su personal desde la segunda quincena de abril de 2017. Esta falta de operatividad de la misión ha llevado a realizar un estudio a finales de 2016, que concluyó con el desmantelamiento de algunos de los puestos a otras misiones en Uganda e Italia ${ }^{82}$. Además, como indica el

\footnotetext{
79 Ibid., párr. 70.

80 Resolución 2285 del Consejo de Seguridad de las Naciones Unidas, de 29 de abril de 2016.

81 Informe del Secretario General sobre la situación en el Sáhara Occidental, 10 de abril de 2017, S/2017/307, párr. 14.

82 Ibid., párr. 16.
} 
Secretario General «el hecho de que la Misión no funcionara a plena capacidad ha sido considerado un impedimento a sus actividades debido a que cada vez se exige más a los observadores militares que realicen tareas de apoyo ${ }^{83}$. Igualmente, tras la crisis de Guerguerat, se ha producido un «aumento de las críticas de ambas partes a la MINURSO y a las Naciones Unidas por su supuesta incapacidad para resolver el estancamiento» ${ }^{84}$.

En estas circunstancias, cabe preguntarse si el escueto mandato de la misión tiene aún razón de ser, contribuyendo de manera eficaz al proceso de paz. Las tensiones en Guerguerat han sido la última clave para refrendar que la MINURSO no ha estado en disposición de prevenir o evitar las diferentes rupturas del alto el fuego como no ha estado tampoco en su plena capacidad durante algo más de un año. La expulsión por parte de Marruecos de una gran parte del componente civil de la misión ha puesto en duda su papel de pacificadora, posicionándose más bien como un elemento de tensión y disputa entre las partes. A ello hay que sumar, la negativa del Consejo de Seguridad de ampliar el mandato y hacerlo más coherente con las circunstancias del conflicto. Todo ello ha tenido su correlato en la Resolución 2414 (2018) del Consejo de Seguridad, en la que la renovación de la MINURSO se ha visto reducida a la mitad del tiempo (hasta el 31 de octubre de 2018). Esto ha supuesto un cambio de tendencia en la política seguida en el Consejo de Seguridad desde el año 2008, que da pistas muy claras sobre las dificultades que supone continuar con la inercia de prórrogas a la misión, que cada vez parece más inoperante y costosa a muchas niveles.

Por todo ello, la MINURSO debería ceñirse a su mandato original o, en caso de que esto no fuera posible, extinguirse como tal, dada la incoherencia, inconsistencia y limitación de su mandato. En su lugar debería desplegarse otra misión multidimensional e integrada, con un enfoque diferente y nuevo, acorde con los principios que rigen las operaciones de paz de Naciones Unidas del nuevo siglo.

\subsubsection{Analogías en la posibilidad de administración internacional}

Evidenciada la incapacidad de la MINURSO para contribuir eficazmente a fin del conflicto entre Marruecos y el Frente Polisario, hay que considerar cuáles serían las herramientas más capaces de desbloquear el

\footnotetext{
83 Ibid., párr. 17.
}

84 Ibid., párr. 54. 
proceso de autodeterminación interrumpido. Desde un punto de visto jurídico-internacional, existen posibilidades que contribuirían enormemente al avance del proceso de paz y que ya han sido llevadas a la práctica en otros contextos. Entre ellos se contaría la negociación de una salida al mar en el territorio controlado por el Frente Polisario, que pudiera hacer posible la libre circulación de la población saharaui que vive en los campamentos de refugiados de Argelia por el territorio que se encuentra bajo control marroquí, eliminándose a su vez el muro que separa ambos territorios y divide a la población saharaui.

Por otro lado, la Comunidad Internacional ha mostrado algunos ejemplos de «administración temporal» de territorios en situaciones transicionales, como Timor Leste o Kosovo. Esta sería, desde la perspectiva jurídico-internacional (no necesariamente factible políticamente), la mejor opción para la controversia del Sáhara de manera neutral y respetuosa con los derechos humanos y el derecho de libre determinación.

La práctica de las Naciones Unidas en este sentido demuestra un alto porcentaje de éxito en disputas de rasgos muy similares, como el conflicto de Timor Leste. En 1999, el Consejo de Seguridad de las Naciones Unidas, a través de su Resolución 1272 establecía la United Nations Transitional Administration in East Timor (UNTAET) ${ }^{85}$, como una misión integrada y multidimensional que operaría como completo responsable de la administración del territorio durante su transición a la independencia. El resultado de la administración temporal internacional de Timor Leste durante un período de tiempo menor a tres años fue fructuosa, consiguiéndose su transición hacia la independencia en 2002.

El segundo ejemplo de administración internacional de un territorio es el de la UNMIK (United Nations Interim Administration Mission in Kosovo $)^{86}$, creada también en 1999 mediante la Resolución 1244 (1999) del

85 UNTAET es una operación con un componente de gobierno administrativo y un componente de policía civil que asciende a 1640 personas así como una misión de mantenimiento de la paz, de tamaño equivalente a la INTERFET. Además, en la administración transicional se incorporaron la asistencia humanitaria y componentes para la rehabilitación. Para financiar estas actividades transicionales de la Administración Internacional se celebró una conferencia especial de donantes en Tokio en diciembre de 1999, que recaudó más de 520 millones de dólares (vid., http://www.un.org/en/peacekeeping/missions/past/etimor/UntaetB.htm).

86 Después de la declaración de independencia la misión continúo desarrollando algunas de sus responsabilidades en el territorio contando con un personal uniformado de 16 personas, 219 personas como efectivos locales y 24 personas como voluntarios de las Naciones Unidas. 
Consejo de Seguridad de las Naciones Unidas. Establecía una administración provisional mientras que se creaban instituciones democráticas de autogobierno en el territorio. La misión desempeñaba funciones administrativas y facilitaba el proceso político, entre otros objetivos clave. La consumación de la UNMIK fue la declaración de independencia de Kosovo en el año $2008^{87}$. Sin embargo, las Naciones Unidas no han admitido como Estado miembro hasta el momento a Kosovo (ni esta opción parece realista a corto plazo), aunque sí ha habido numerosos Estados que le han otorgado reconocimiento.

En el conflicto del Sáhara Occidental, es relevante considerar la posibilidad de una administración temporal del territorio hasta que la población saharaui vuelva progresivamente a sus hogares en colaboración con organismos regionales e internacionales. Esto estaría directamente ligado a la necesaria reformulación de la MINURSO en una misión integrada y multi-dimensional con capacidades administrativas amplias y mecanismos de protección de los Derechos Humanos.

Si bien es cierto que, pensando en términos político-diplomáticos, es muy complicada esta ampliación de mandato y la idea de una administración internacional, no sería descabellado pensar que, dada la situación actual, esta misión deba ser eliminada (tal y como está formulada), ya que no hay ninguna evidencia de sus logros en el proceso, pero sí de ser un elemento más de disputa entre las partes. En el Sáhara Occidental la MINURSO debe evolucionar necesariamente, hacia su ampliación o, en su defecto, su extinción.

En el devenir de otros conflictos internacionales, hay algunos ejemplos de misiones cuyas circunstancias han cambiado sobremanera y entonces el mandato ha sido reenfocado y reformulado, cuando no ha quedado extinto. En cualquier caso, el mandato actual no es adecuado a la controversia internacional, que además ha sufrido un nuevo avivamiento de la violencia tras sufrir no pocos menoscabos del alto el fuego, la expulsión temporal de gran parte del componente civil de la MINURSO. Del mismo modo, ha tenido que lidiar con el reciente deceso del histórico líder del Polisario, Mohamed Abdelaziz, quien declaró poco antes de su muerte al Secretario General Ban Ki Moon que $\ll$ el Frente Polisario no excluiría volver a la lucha armada» ${ }^{88}$.

\footnotetext{
87 VV.AA., Malvinas y la construcción de un reclamo soberano. Pasado, presente y futuro, Universidad Nacional de la Plata, 2017, pp. 296.

88 Report of the Independent Expert on human rights..., ibid., párr. 11.
} 


\section{El PAPEL DE LA UNIÓN AFRICANA EN EL PROCESO DE PAZ: DIPLOMACIA INACTIVA Y CÓMO LA MARGARITA DIJO SÍ A MARRUECOS AL FINAL DEL CUENTO}

Es una cuestión poco debatida cuál ha sido el papel de la Organización para la Unidad Africana (OUA) y cuál es el papel de la Unión Africana (UA) en la gestión del conflicto y del proceso de paz en el Sáhara. Los principios y valores de ambas organizaciones regionales destacan por su enfoque comunitarista, su énfasis en el concepto de pueblo y su defensa del derecho de libre determinación. Por ello, en sus inicios la OUA fue baluarte de muchas causas anticolonialistas y defendió también con ahínco la del pueblo sahariano. Su mayor prueba (de fe) fue el reconocimiento de la República Árabe Saharaui Democrática (RASD) como Estado miembro de pleno derecho en 1976, un año después de que el Frente Polisario autoproclamara el Estado en el territorio de Bir Leblu, que había liberado durante el conflicto armado, lo que terminaría por provocar la retirada voluntaria de Marruecos de la Organización.

Más de 40 años después, y con la organización regional reconvertida en la $\mathrm{UA}^{89}$, Marruecos ha sido admitido como Estado miembro, entrando de nuevo a formar parte del foro regional africano, del que voluntariamente permaneció aislado durante décadas. Las siguientes líneas se proponen elucidar las cuestiones jurídicas subyacentes a sendas membresías, así como examinar cuál ha sido en realidad el papel de las organizaciones regionales africanas en el avance del conflicto.

\subsection{La RASD: no sin mi Estado. Los problemas de la bicefalia}

Con la admisión de la República Árabe Saharaui Democrática como Estado miembro en la OUA en 1982, el reconocimiento otorgado al Frente Polisario como movimiento de liberación nacional fue interrumpido. Con ello, la posibilidad de que fuera establecido un estatuto apropiado al movimiento en el seno de las Naciones Unidas se limitó. De acuerdo con el Derecho Internacional, el único requisito para que un Movimiento de Liberación Nacional

\footnotetext{
89 Assembly/AU/Dec.639(XXVIII) 28th Ordinary Session of the Assembly of the Union, 30-31 January 2017, Addis Ababa, accesible en: https://au.int/sites/default/files/decisions/32520-sc19553_e_original_-_assembly_decisions_621-641_-_xxviii.pdf.
} 
(MLN) obtuviera un estatuto de observador en la ONU es que la organización regional correspondiente (en aquel momento, la OUA) le enviara información sobre este aspecto, confirmando la condición de MLN del Polisario. De hecho, la OUA envió a Naciones Unidas en 1974 un documento con el reconocimiento de trece MLN a través del Comité de Coordination pour la libération de l'Afrique ${ }^{90}$. La ausencia del Frente Polisario de este documento se debió a que en 1974 aún no se había consolidado con la suficiente fuerza como para ser conocido y reconocido a nivel regional, pues en 1974 España aún ejercía se encontraba en el territorio y lo administraba, y el movimiento era clandestino. Un año después, el paso inadvertido de la Misión de Visita (que concluyó con dicha calificación) y la proclamación de la RASD contribuyeron a minimizar la relevancia del Polisario a escala regional e internacional.

Por su parte, el recorrido de la RASD por la organización regional africana continuó tras disolverse la OUA en el año 2000 y crearse la Unión Africana $(\mathrm{UA})^{91}$, de la cual la república saharaui es Estado miembro originario. En este escenario regional, tener un asiento en la OUA y en la UA ha hecho problemático que el Frente Polisario puede tener legitimidad como movimiento de liberación nacional saharaui en África, pasando a diluirse bajo la estela de las RASD y sus formalidades de Estado ${ }^{92}$. El Consejo de Ministros de la desparecida OUA declaró a este respecto que «Le Polisario ne pouvait plus être reconnu par l'OAU en tant que mouvement de libération nationale $\gg^{93}$. Y ello, precisamente, por el reconocimiento formal de la RASD como Estado, y su consideración, por ende, de soberano africano, lo que a todas luces parece evidenciar como innecesario un reconocimiento al Polisario.

90 incluyendo al PAIAGG (Partido Africano para la Independencia de Guinea y Cabo Verde), FRELIMO (Frente de Liberación de Mozambique), MPLA (Movimiento Popular de Liberación de Angola), FNLA (Frente Nacional de Liberación de Angola), UNITA (Unión Nacional para la Independencia Total de Angola), SWAPO (South West Africa People's Organisation), ZAPU (Zimbabwe African People's Union), ZANU (Zimbabwe African National Union), ANC (African National Congress), PAC (Pan African Congress), MOLINACO (Mouvement de libération national des Comores), SPUP (Seychells' People Union Party) y FLCS (Front de libération de la Côte des Somalis).

91 El tratado constitutivo del a Unión Africana fue adoptado en Lomé en el año 2000, por parte de 53 Estados fundadores, incluyendo a la RASD, y entrando en vigor en el año 2001. http://www. au.int/en/sites/default/files/ConstitutiveAct_EN.pdf.

92 Además del reconocimiento de la OUA y la UA, un alto porcentaje de Estados africanos $y$ de otras regiones) ha reconocido a la RASD, teniendo embajadas en su territorio y estableciéndose entre ellos auténticas relaciones Estado-Estado.

93 Décision du Conseil de Ministres á sa 26 a session, Addis Abeba, 28 février 1976. 
En esta situación jurídica particular, nos encontramos ante una contradicción que ha podido terminar afectando a los derechos del pueblo saharaui. El reconocimiento pleno de la RASD como Estado por la OUA y, posteriormente, por la UA, hace complicada la coordinación de éstas con las Naciones Unidas, para quien el representante legítimo del pueblo saharaui no es otro que el Frente Polisario. Éste, en su calidad de movimiento de liberación nacional, tendría como objetivo principal aspiración de estatalidad tras el ejercicio de la autodeterminación. Por ello, quedaría poco clara la postura de la organización regional africana frente a sendas cuestiones (aspiración de estatalidad y autodeterminación) y a su proceso su realización. Considerar que la RASD es un Estado libre y soberano puede ser contraproducente si se quiere, en el fondo, defender su derecho de libre determinación, propósito que, no obstante, está en la base del reconocimiento otorgado por la OUA y la UA. La confusión jurídica creada puede favorecer visiones distorsionadas del conflicto. En efecto, el Gobierno de Marruecos ha argumentado que no se trataría de un conflicto internacional sino interno, ya que si se ha producido la autoproclamación de un Estado, no hay ningún caso de descolonización pendiente ${ }^{94}$. Por todo ello, el reconocimiento de la RASD ha causado una práctica confusa que afecta a una cuestión fundamental como es quién debe ser considerado el legítimo representante de pueblo saharaui. La proclamación del Estado creó un binomio, pero la pretensión del Frente Polisario era crear dos herramientas complementarias que coadyuvaran a la consecución de la autodeterminación. La forma de Estado proporciona a la causa saharaui una mayor facilidad a la hora de establecer relaciones bilaterales o multilaterales en la Comunidad Internacional, habiendo obtenido hasta el momento más de ochenta reconocimientos de Estados.

Las Naciones Unidas contribuyeron a desarrollar y definir esta categoría de sujetos con su práctica. Los movimientos de liberación nacional, una vez insertados en el sistema de la Organización, obtienen normalmente los algunos derechos ${ }^{95}$. En primer lugar, adquieren el estatuto de único y legítimo representante de un pueblo. Este privilegio debe ser mejor considerado como una precondición, que se formaliza con el reconocimiento como tal. Para ello, el MLN debe ser reconocido como de importancia revolucionaria o histórica.

94 Vid. Declarations of Moroccoan Goverment in Report of the Secretary-General on the situation concerning Western Sahara, 19 April 2016, S/2016/355.

95 Soroeta Liceras, J., El Sábara Occidental. Reflejo de las contradicciones y carencias del Derecho Internacional, Bilbao, 2001, pp. 370, p. 28. 
Su representatividad puede ser considerada como una aplicación del principio de efectividad, en tanto que sea aceptado por los organismos internacionales ${ }^{96}$. En segundo lugar, pueden obtener el estatuto de observador en las Organizaciones Internacionales ${ }^{97}$, que lleva intrínsecamente aparejados otra serie de derechos en cada una de ellas. En las Naciones Unidas, los MLN una vez reconocidos como observadores pueden ser receptores de los programas de ayuda humanitaria de Naciones Unidas y el sistema de Naciones Unidas ${ }^{98}$, tienen libre acceso a reuniones y documentos y pueden participar en las sesiones que conciernan a su causa. Dado que se trata de un mecanismo regulado en exclusiva por la práctica de la Organización, no se encuentra en la Carta ninguna disposición al respecto.

Precisamente por esta ausencia de regulación positiva, puede ocurrir que algunos MLN no reciban de manera efectiva la legitimidad para ejercer tales derechos. La razón puede encontrarse, como se mencionó anteriormente, en el sistema de intercambio de información de Naciones Unidas con las organizaciones regionales, que deben enviarle para certificar la existencia de un MLN. ABI-SAAB, en un intento de subrayar la posibilidad de que existan intereses políticos en esta comunicación entre instituciones internacionales, apunta que «the regional Organizations, for obvious reasons, only recognize liberation movements whose adversary lies outside the membership of the organization». Por esto, considera que «the regional organization shouldn't be the only arbiter in identifying and national liberation movements ${ }^{99}$.

En el Preámbulo de la Constitución de la RASD se establece que el pueblo saharaui «resolve to continue the struggle for the completion of the sovereignty of the Sahrawi Arab Democratic Republic on the entire national territory $\gg^{100}$. Sin embargo, las dudas parecen persistir en las Naciones Unidas, quedando patente que el lugar del Frente Polisario en la Organización no se corresponde con los derechos y deberes pertenecientes a un MLN.

96 ThIERRY, H., «L'évolution du droit International», 222 RCADI, 1990-III, pp. 9-186.

97 SUY, E., «The Status of Observer in International Organizations», 160 RCADI, 1978-II, pp. 75 180.

98 BARBeris, J. A., Los sujetos de Derecho Internacional actual, Madrid, 1984, pp. 204.

99 ABI-SAAB, G., «Wars of National Liberation in the Geneva Conventions and Protocols», 165 RCADI, 1979 IV, pp. 363-445, p. 408.

100 La tercera Constitución de la RASD se proclamó durante el X Congreso del Frente Polisario del 26 de agosto al 4 de septiembre de 1999. Se puede consultar en: http://www.arso.org/03const.99.htm. La primera Constitución de la RASD se adoptó tras la proclamación del Estado en 1976, y la segunda en 1990. 
Además, por la inadecuada prolongación del conflicto hasta su catalogación como intractable conflict, una entidad que se fundamenta en su propia transitoriedad se ha visto obligada a permanecer en la condición de representante del pueblo saharaui por más de cuarenta años, lo cual es a todas luces una situación contra natura de la condición de MLN. Resulta interesante examinar si este estatus puede permanecer inalterado en el tiempo hasta la consecución de la libre determinación o, por el contrario, este reconocimiento debe tener un seguimiento y control para asegurar que esta condición no está caduca o que las circunstancias del territorio han cambiado fuertemente con el paso del tiempo y el movimiento se haya debilitado.

En este sentido, vale la pena pararse a considerar el caso de la Organización para la Liberación de Palestina. Aunque su condición de observadora permanente era una de las más sólidas de los MLN en el mundo, ha sido patente su lucha de poder con otros órganos dentro de los territorios palestinos que le han disputado la representación del pueblo, incluso con fuertes confrontaciones de ideas y planteamientos sobre el conflicto ${ }^{101}$. Si bien es cierto que la Palestina es hoy un Estado observador (aunque no miembro de pleno derecho) en las Naciones Unidas ${ }^{102}$ y el protagonismo de la OLP ya no es relevante y, además, las diversas facciones del nacionalismo palestino (Al Fatah y Hamás) han decidido recientemente unificar sus esfuerzos llegando a un acuerdo de reconciliación en octubre de $2017^{103}$, sí que conviene señalar las posibles derivaciones que, por la naturaleza de los territorios no autónomos, tienden a la evolución de los planteamientos políticos, sociales y humanos de una ocupación extranjera por mucho más tiempo que el deseable. Esto ha llevado a que generaciones completas hayan pasado sus vidas políticas inmersas en un proceso (de descolonización, de paz, de negociación ¿? $)^{104}$ liderado por un MLN cuya vida se esperaba corta y transitoria, y que ahora quizás se ha

101 GUARINO G., «Personalità giuridica di diritto internazionale: il caso dell’Organizzazione per la Liberazione della Palestina», en Studi di diritto internazionale in onore di Gaetano Arangio-Ruiz, Napoli, 2005.

102 Resolución 67/19 de la Asamblea General de las Naciones Unidas, de 29 de noviembre de 2012.

$103 \mathrm{http}: / /$ www.un.org/spanish/News/story.asp?newsID=38276\#.WfnFP0we48Y.

104 Sobre este particular vid., entre otros: Fiddian-Qasmiyeh, E., The ideal refugees. Gender, Islam and the Sabrawi Poltics of Survival, Siracurse University Press, 2014, pp. 329; FERNÁNDEZ-GómEZ, M., Struggling for Liberation in the Sabaraui Refugee Camps: a Generational an Gender Perspective, Thesis, Georgetown Univeristy, 2012, pp. 126; CARATINI, S., «La prison du temps. Les mutations sociales à l'œuvre dans les camps de réfugiés sahraouis», Afrique Contemporaine, 221, 2007, pp. 153-172. 
revelado como institución demasiado longeva. En todo caso, está en la naturaleza de los MLN su temporalidad, su función de bisagra entre el pueblo y la libre determinación ansiada. $\mathrm{Y}$ es precisamente la ruptura de esa transitoriedad y el estancamiento de los mecanismos de arreglo pacífico lo que provoca su catalogación como intractable conflict.

Por su parte, el Frente Polisario sigue haciendo un uso correcto y apropiado de su condición de MLN en la Comunidad Internacional. Como ejemplo, la ratificación de las Convenciones de Ginebra 1949 y sus Protocolos Adicionales de 1966 en el año $2105^{105}$. Igualmente, su intención de ratificar el Estatuto de Roma de la Corte Penal Internacional parece cada vez más probable, teniendo en cuenta el precedente de Palestina ${ }^{106}$. En la práctica, la firma y ratificación de tratados internacionales por movimientos de liberación nacional sigue siendo un atributo más de su subjetividad. En cuanto al derecho de legación activo y pasivo, sus contactos internacionales con Estados y Organizaciones Internacionales llevan un largo tiempo siendo estables, así como complementarios con los de la RASD, en forma de embajadas y consulados en aquellos Estados y Organizaciones que les han otorgado reconocimiento. El ejercicio de estos derechos propios de la subjetividad internacional confirma que en la práctica el Frente Polisario continua siendo el representante del pueblo saharaui en la Comunidad Internacional.

\subsection{Aportaciones africanas al proceso de paz}

La ausencia de Marruecos en el foro regional africano durante más de treinta años acrecentó su aislamiento en el continente, pese a contar con algunos Estados que antepusieron los intereses comerciales con el Reino alauita a la cuestión saharaui, como Senegal o Burkina Faso. Pese a ello, ningún Estado africano ha reconocido soberanía alguna de Marruecos sobre el territorio del Sáhara.

105 Notification to the Governments of the States parties to the Geneva Conventions of 12 August 1949 for the Protection of War Victims, 242.512.0 - GEN 4/15, de 26 de junio de 2015.

«Conformément à l'article 96.3 du Protocole additionnel aux Conventions de Genève du 12 août 1949 relatif à la protection des victimes des conflits armés internationaux (Protocole I) du 8 juin 1977, le Front Polisario, en tant qu'autorité représentant le peuple du Sahara Occidental luttant pour son droit à disposer de lui-même, déclare s'engager à appliquer les Conventions de Genève de 1949 et le Protocole I dans le conflit l'opposant au Royaume du Maroc.»

106 Palestina aceptaba la competencia de la Corte Internacional de Justicia en enero de 2015: https://www.icc-cpi.int/palestine. 
Pero este alejamiento marroquí de las organizaciones internacionales regionales pudo haber sido parcialmente aliviado con la Unión del Magreb Árabe ${ }^{107}$, que pretendía crear lazos comerciales y políticos entre los Estados del norte de Africa. Sin embargo, de nuevo la cuestión saharaui estuvo en el centro de las disputas entre Marruecos y Argelia, lo que terminó por quebrar el frágil lazo que unía los intereses de uno y otro y por bloquear las reuniones de la Organización desde 1994. La OUA consideró el reconocimiento de la RASD como su mayor aportación al proceso de paz del Sáhara Occidental. Previamente, en 1978, había creado un Comité ad hoc para buscar una salida al contencioso, enviando una misión visitadora al territorio. Ya en 1983 publicaría su primer Plan de Acción ${ }^{108}$ en el que pide a Naciones Unidas el establecimiento de una operación de paz e intenta activar el proceso de paz basado en el referéndum.

Por su parte, la UA, ha admitido como Estado miembro a Marruecos, lo que ha sido visto como un nuevo impulso al proceso de paz a escala regional. Poco antes, en septiembre de 2016 la UA se pronunciaba con preocupación sobre los incidentes ocurridos en Guerguerat, pidiendo la vuelta de la MINURSO a su plena capacidad. La Asamblea y el Comité Ejecutivo de la OUA han solventado la cuestión saharaui teniendo un papel secundario a lo largo de los años, limitándose a pedir el cumplimiento de las resoluciones de las Naciones Unidas y la celebración del referéndum de libre determinación, así como aportando breves actualizaciones del estado de la cuestión en sus sesiones. En 2009, la UA fue algo más ambiciosa y adoptó un Plan de Acción con el que se colocaba como buena oficiante del proceso de paz en el marco de una sesión extraordinaria celebrada en Trípoli sobre los conflictos en África. En este, volvía a apoyar la línea marcada por la ONU e insistía en la opción de un referéndum que contemplara la opción de la independencia. El papel de la OUA y, más tarde de la UA, como agente colaborador en la MINURSO ha llevado a que hoy en día aún persista una oficina de la Organización en el territorio del Sáhara, lo que le permite tener cierto acercamiento a la cuestión y recibir información de primera mano sobre el estado del conflicto.

Otra cuestión en la que destaca la participación de la UA es en la denuncia de las violaciones de derechos humanos. En marzo de 2017, ya cuan-

\footnotetext{
${ }^{107}$ La Unión del Magreb Árabe (UMA) se funda en 1989 por cinco Estados: Marruecos, Argelia, Túnez, Libia y Mauritania. Sitio web de la Organización: http://www.maghrebarabe.org/en/ marrakech.cfm.

108 A través de la resolución AHG/Res.104(XIX).
} 
do Marruecos había sido admitido como miembro de la Organización, el Enviado Especial para el Sáhara Occidental, el antiguo Presidente de Mozambique Joaquim Chissano, ponía sobre aviso en la $34^{a}$ sesión del Consejo de Derechos Humanos de las Naciones Unidas sobre la preocupante situación y la necesidad urgente de controlar dichas conductas ${ }^{109}$. En 2012 la Comisión Africana de Derechos Humanos y de los Pueblos realizó una visita para examinar la situación de los Derechos Humanos, y en 2016 el Consejo de Paz y Seguridad le encomienda la realización de otra visita a los campamentos de Tindouf, con el objetivo de extraer información y realizar recomendaciones al Consejo ${ }^{110}$.

El Consejo de Paz y Seguridad ha venido ocupándose de la cuestión en sus diferentes sesiones con unas líneas bastante claras: apoyo a las negociaciones patrocinadas por Naciones Unidas, vuelta de la MINURSO a su mandato original con la celebración de la consulta de autodeterminación (contemplando la independencia como una opción) y, además apoyo a la ampliación del mismo en los siguientes términos «Council urges the UN Security Council to take the necessary steps to provide MINURSO with a human rights mandate ${ }^{111}$. Igualmente, destaca su continua crítica a la expoliación de los recursos naturales del territorio recomendando incluso «a strategy of global boycott of products of companies involved in the illegal exploitation of the natural resources of Western Sahara» ${ }^{112}$.

Para ello el Consejo de Paz y Seguridad decidió reactivar en su sesión de 2015 la actividad del Comité ad hoc que ya se había establecido en el $1978^{113}$, pero que llevaba décadas inactivo. Además, en la misma resolución, el Consejo de Paz y Seguridad decide establecer un Grupo Internacional de Contacto sobre el Sáhara Occidental (ICG-WS, por sus siglas en inglés), así como incrementar su presencia en el conflicto comenzando a ocuparse de la cuestión un mínimo de dos veces al año.

109 PRESS RELEASE, African Union Special Envoy for Western Sahara, H.E. former President Joaquim Chissano conducts consultations on Western Sahara in Geneva, Switzerland, Addis Ababa, 3 March 2017.

110 PSC/PR/COMM/1.(CDXCVI), PEACE AND SECURITY COUNCIL, 496TH MEETING, ADDIS ABABA, ETHIOPIA, 27 MARCH 2015. Communiqué, párr. 10.

111 Ibid., párr. 9.

112 Ibid., párr. 11.

113 Este Comité estaría ahora formado por 10 Jefes de Estado y de Gobierno con una distribución equitativa de las cinco regiones de África. 
Por otro lado, la Comisión sobre la evolución del proceso de paz en el Sáhara Occidental (en adelante, la Comisión) tiene encomendada la labor de «take all necessary measures for the organization of a referendum for the self-determination of the people of Western Sahara, in compliance with the relevant decisions of the Organization of African Unity (OAU) and United Nations (UN) resolutions». Además su Presidente se encarga de elaborar informes detallados sobre la situación desde 2013 y de mantener contactos con los representantes de las partes, Marruecos y la RASD, lo que parece corresponder al médio de arreglo pacífico de «investigación».

En el intercambio de correspondencia entre Chissano y Marruecos destaca la negativa de éste último de aceptar rol alguno de la UA en el proceso de paz ${ }^{114}$, actitud que no se sustentaría en la actualidad con Marruecos como miembro de la Organización. Además, el Presidente de la Comisión ha mantenido contactos con el Secretario General de las Naciones Unidas y su Enviado Especial, los representantes de los miembros permanentes del Consejo de Seguridad, además de con los de Argelia, Mauritania y España ${ }^{115}$. Fue éste también quien realizó el nombramiento de Chissano como Enviado Especial para el Sáhara Occidental en 2014, quien se ocuparía de continuar con la ronda de contactos a los mandatarios internacionales ${ }^{116}$, de la que destacarían la conclusión de estancamiento del proceso y el establecimiento de dos líneas prioritarias de actuación: la situación de los derechos humanos y la explotación de los recursos naturales.

En efecto, la organización regional africana ha aportado cierta confusión al conflicto con el reconocimiento de la RASD primero y, con la admisión de Marruecos por último. Además, sus esfuerzos diplomáticos han sido insuficientes pese a la rotundidad de algunas declaraciones en las dos cuestiones principales: las violaciones de Derechos Humanos y la explotación de los recursos naturales, sin establecerse una línea clara de compromiso ahora que las dos partes del conflicto son miembros de pleno derecho en la Organización.

\footnotetext{
114 «the Foreign Minister of Morocco, in a letter dated 6 May 2013, objected to any specific AU role, stressing that all concerned, particularly in Africa, should support and encourage the efforts of the UN Security Council and the Secretary-General», párr. 15.

115 Ibid., parr. 17.

${ }^{116}$ From 11 to 17 June 2014, the Special Envoy undertook visits to London, Paris, Madrid, Washington and New York, to consult with the relevant British, French, Spanish, US and UN officials. From 6 to 10 September 2014, he visited Moscow, for discussions with Russian officials. From 19 to 22 January 2015, he went to Beijing, where he held consultations with relevant Chinese officials. The Special Envoy had fruitful discussions with all his interlocutors». Ibid., párr. 19.
} 


\section{Conclusiones}

El territorio del Sáhara Occidental sigue estando considerando como Territorio no Autónomo en las Naciones Unidas, por lo que «se espera» la aplicación del derecho de libre determinación de los pueblos por parte de la Comunidad Internacional. Sin embargo, desde hace más de una década el Consejo de Seguridad y el Secretario General optan por recomendar como medio de arreglo pacífico en solitario la negociación entre las partes sin que haya habido ningún progreso. Es necesaria la recomendación de otros medios de arreglo pacífico que puedan respetar el derecho de libre determinación como base en la gestión del conflicto y, en su caso, fijar un nuevo acuerdo de paz que sustente unas negociaciones complementarias basadas en la buena fe.

Para ello, en primer lugar urge el re-enfoque de la MINURSO, cuando no su plena extinción y creación de una nueva OMP multidimensional e integrada, que responda a las necesidades de la controversia. Como herramienta más eficaz desde el estudio de la práctica, es necesario considerar la posibilidad de instalar una administración internacional en el territorio de manera temporal y abrir un corredor humanitario desde los campamentos de Tindouf hasta el mar.

La Unión Africana debe gestionar ecuánimemente la membresía de la RASD y el Frente Polisario en su seno, sin dejar por ello de seguir las recomendaciones de las Naciones Unidas y su constante apoyo a la libre determinación de los pueblos. Habrá que observar si la RASD sigue conservando su estatus en la organización regional africana, así como si se sigue produciendo el seguimiento (hasta ahora inalterado) a sus planteamientos sobre el contencioso.

En el Frente Polisario es urgente una regeneración democrática que sea capaz de aglutinar las aspiraciones de la mayor parte de la población saharaui, ya se encuentren en el Sáhara Occidental o fuera de él. La unificación con sectores de la población descontentos por la falta de resultados del movimiento es vital para evitar una fragmentación del mismo. La esencia de un MLN es su condición de representante «único», y hasta la consecución de la libre determinación, lo cual es su cometido principal, debe no disputarse esta condición con otros movimientos que puedan surgir a nivel interno.

El conflicto del Sáhara Occidental responde a la naturaleza y catalogación de intractable conflict con los actuales parámetros de gestión, que son precisamente los que han propiciado el estancamiento. Es ineludible un cambio de óptica en la resolución del contencioso saharaui en la Comunidad Inter- 
nacional en su conjunto si de verdad se quiere llegar a una posible salida a la compleja situación que lleva enquistada más de cuarenta años. Ello pasa por aceptar la inadecuación de la negociación como medio principal de arreglo pacífico en esta controversia, así como la retroalimentación del conflicto que produce la continuación pseudo-automática de la MINURSO sine die con un mandato incoherente e ineficaz. Tanto a nivel universal como regional, es necesario concentrar los esfuerzos de resolución en la consecución de un nuevo acuerdo de paz que tenga en cuenta la situación especial que atraviesan los derechos humanos y los recursos naturales del pueblo saharaui.

\section{REFERENCIAS BIBLIOGRÁFICAS}

ABI-SAAB, G., «Wars of National Liberation in the Geneva Conventions and Protocols», 165 RCADI, 1979, IV, pp. 363-445, p. 408.

BAR-TAL, D., «Societal Beliefs in Times of Intractable Conflict: The Israeli Case», International Fournal of Conflict Management, vol. 9, issue 1, 1998, pp. 22-50.

BARBERIS, J. A., Los sujetos de Derecho Internacional actual, Madrid, 1984, pp. 204.

BARSH, R. L., «Indigenous People in the 1990s: from object to subject of International Law?», Harvard Human Rights fournal, 7, 1994.

CARATINI, S., «La prison du temps. Les mutations sociales à l'œuvre dans les camps de réfugiés sahraouis», Afrique Contemporaine, 221, 2007, pp. 153-172.

Clark, D; Williamson, R., Self Determination. International Perspectives, Springer, 2016, pp. 443.

Coleman, T., «Intractable Conflict as an attractor: a Dinamical System Approach to Conflict Escalation and Intractability», American Behavioral Scientist, vol. 50, issue 11, 2007, pp. 1454-1475.

FERnandeZ-Gómez, M., Struggling for Liberation in the Sabaraui Refugee Camps: a Generational an Gender Perspective, Thesis, Georgetown Univeristy, 2012, pp. 126.

Fiddian-QAsmiyen, E., The ideal refugees. Gender, Islam and the Sabrawi Poltics of Survival, Siracurse University Press, 2014, pp. 329.

Gifra Dural, J., «La reforma de los procedimientos especiales del Consejo de Derechos Humanos: ¿una mejora en los mecanismos extra convencionales?», Anuario de Derechos Humanos. Nueva Época, vol. 3, 2009, pp. 223-259.

Glozman, E. et al., «False Negotiations. The Art and Science of Not Reaching an Agreement», Fournal of Conflict Resolution, Vol. 59, Issue 4, 2015, pp. 671-697.

GONZÁLEZ FARIETA, F. et al., «El papel de la ONU en el conflicto del Sáhara Occidental», Comunicación, Cultura y Política. Revista de Ciencias Sociales, vol. 1, nº 2, 2009, pp. 111-124.

GUARINO G., «Personalità giuridica di diritto internazionale: il caso dell'Organizzazione per la Liberazione della Palestina», en Studi di diritto internazionale in onore di Gaetano ArangioRuiz, Napoli, 2005.

KoLb, R., Théorie du ius cogens international. Essai du relecture du concept, Graduate Institute Publicacions, 2015, pp. 404.

MareIKE, P., «The conflict of Western Sahara. The role of the United Nations in resolving it», Term Paper, Otto-von-Guericke University Magdeburg, 2016, pp. 18. 
Massé, F., «Negociaciones de paz y causa de los conflictos», Ultimátum, Revista Zero, p. 5055.

Olásolo, H., «La inseguridad jurídica de los acuerdos de paz a la luz del régimen jurídico internacional de los crímenes de ius cogens y la justicia de transición», Politica Criminal, vol. $12, \mathrm{n}^{\circ} 23,2017$, pp. 78-102.

RICE, P., «The Finite Negotiation Problem. A Solution Theory», Fournal of Conflict Resolution, vol. 23, issue 3, 1979, pp. 561-576.

Rogoff, M. A., «The Obligation to Negotiate in International Law. Rules and Realities», Michigan fournal of International Law, vol. 16, issue 1, 1994, pp. 141-186.

Ruiz Miguel, C., «La propuesta marroquí de autonomía para el Sáhara de 2007: una antigua propuesta sin credibilidad», REAF, $\mathrm{n}^{\circ} 7$, octubre, 2008, pp. 268-291.

Shea, P. E; Christian, C., «The Impact of Women Legislators on Humanitarian Military Interventions», Fournal of Conflict Resolution, vol. 61, issue 10, 2017, pp. 2.43-2073.

Solá Martín, A., «The Contribution of Critical Theory to New Thinking on Peacekeeping. Some Lessons from MINURSO», Working Paper 15, University of Bradford, 2015, pp. 18.

Soroeta LicERAS, J., «El conflicto del Sáhara Occidental en el contexto del nuevo orden internacional», Revista Española de Derecho Internacional, 54, n 1, 2002, pp. 491-497.

— «El plan de paz del Sáhara Occidental, ¿viaje a ninguna parte?», REEI, $\mathrm{n}^{\circ} 10,2005$, pp. $1-33$.

- El Sábara Occidental. Reflejo de las contradicciones y carencias del Derecho Internacional, Bilbao, 2001, pp. 370, p. 28.

SuY, E., «The Status of Observer in International Organizations», 160 RCADI, 1978-II, pp. $75-180$.

SzMOLKA, I., «El conflicto del Sáhara Occidental en el marco de la primavera árabe», Revista de Investigaciones Politicas y Sociológicas, vol. 12, nº 2, 2013, pp. 45-64.

THIERRY, H., «L'évolution du droit International», 222 RCADI, 1990-III, pp. 9-186.

ZarTAMn, I. W., «Conflict Resolution and Negotiation», en Bercowith et al. (eds.), The SAGE Handbook of Conflict Resolution, Londres, SAGE, 2009, pp. 682. 